\title{
A mouse translocation associated with Caspr5-2 disruption and perinatal lethality
}

\author{
Dieter Weichenhan • Walther Traut • \\ Christina Göngrich · Heinz Himmelbauer · \\ Lüder Busch · Hannah Monyer · Heinz Winking
}

Received: 19 February 2008/ Accepted: 26 September 2008/Published online: 24 October 2008

(C) The Author(s) 2008. This article is published with open access at Springerlink.com

\begin{abstract}
We have previously described the paralogous mouse genes Caspr5-1, -2, and -3 of the neurexin gene family. Here we present the cytogenetic and molecular mapping of a null mutation of Caspr5-2 which was caused by reciprocal translocation between chromosomes 1 and 8 with breakpoints at bands $1 \mathrm{E} 2.1$ and $8 \mathrm{~B} 2.1$, respectively. The translocation disrupts Caspr $5-2$ between exons 1 and 2 and causes stillbirth or early postnatal lethality of homozygous carriers. Because no other candidate genes were found, the disruption of Caspr5-2 is most likely the cause of lethality. Only rarely do homozygotes survive the critical stage, reach fertility, and are then apparently normal. They may be rescued by one of the two other Caspr5 paralogs. Caspr5-2 is expressed in spinal cord and brain tissues. Despite giving special attention to regions where in
\end{abstract}

D. Weichenhan $(\bowtie)$

Deutsches Krebsforschungszentrum, 69120 Heidelberg, Germany

e-mail: d.weichenhan@dkfz-heidelberg.de

W. Traut $\cdot$ H. Winking

Institut für Biologie, Universität Lübeck, 23538 Lübeck, Germany

C. Göngrich · H. Monyer

Klinische Neurobiologie, Universitätsklinikum Heidelberg, 69120 Heidelberg, Germany

\section{H. Himmelbauer}

Max-Planck-Institut für Molekulare Genetik, 14195 Berlin, Germany

L. Busch

Institut für Anatomie, Universität Lübeck, 23538 Lübeck, Germany wild-type fetuses maximum expression was found, no malformation that might have caused death could be detected in fetal homozygous carriers of the translocation. We, therefore, suspect that Caspr5-2 disruption leads to dysfunction at the cellular level rather than at the level of organ development.

\section{Introduction}

Caspr proteins constitute a family of multidomain transmembrane proteins implicated in cell recognition and cell adhesion (Poliak and Peles 2003). They are predominantly expressed in the nervous system (Peles et al. 1997; Poliak et al. 1999; Spiegel et al. 2002; Traut et al. 2006). Proteins Caspr1 (contactin-associated protein, also designated Caspr, CNTNAP1, or NCP1) and Caspr2 (contactin-associated protein related 2, CNTNAP2) are found mainly at paranodes and juxtaparanodes, respectively, which are specific subdomains of the nodes of Ranvier in myelinated axons. Functional studies revealed that Caspr1, together with contactin, is required for generation of the axoglial junction, whereas targeted disruption of gene Caspr2 leads to a striking reduction in the juxtaparanodal accumulation of specific potassium channels (for review see Poliak and Peles 2003). Both proteins have been implicated in the demyelination and remyelination of axons in patients with multiple sclerosis (Coman et al. 2006; Wolswijk and Balesar 2003). Moreover, CNTNAP2 has recently been identified as a susceptibility gene in autism spectrum disorders (Alarcon et al. 2008; Arking et al. 2008; Bakkaloglu et al. 2008). Structure and subcellular distribution of proteins Caspr3 and Caspr4 suggest a role in cell recognition within the nervous system (Spiegel et al. 2002). 
The least studied gene of the family is Caspr5. We have recently characterized three mouse orthologs, Caspr 5-1, -2, and -3 , of the human CASPR5 gene (Traut et al. 2006). Their multidomain protein structures, as deduced from the nucleotide sequence, are rather similar among each other and to those of proteins Caspr1 to Caspr4. Expression studies revealed overlapping expression patterns, predominantly in nervous tissues. Caspr5-1 and Caspr5-2 map to adjacent loci on chromosome (chr) 1, while Caspr 5-3 maps to chr 17. Caspr 5 genes are rather large, more than $640 \mathrm{~kb}$, and consist of 24 exons.

Animal models containing null mutations by experimental gene knockout are in widespread use to study the function of interesting genes, e.g., candidate genes for human diseases. Loss of gene function can also occur spontaneously by chromosomal rearrangements. Here we describe a reciprocal translocation between mouse chr 1 and chr 8 leading to the disruption of the Caspr5-2 gene. The null mutation in Caspr5-2 causes perinatal lethality in homozygous mutation carriers, while heterozygous animals are phenotypically inconspicuous. Rare survivors among homozygotes suggest functional rescue of Caspr5-2, presumably by either Caspr5-1 or Caspr5-3. Expression analysis revealed that transcription of the three paralogous genes is restricted to partially overlapping areas of the central nervous system. Our data suggest the evolution of diverging gene functions among mouse Caspr5 paralogs after the original Caspr 5 gene had undergone duplications in the rodent lineage.

\section{Materials and methods}

G-banding and fluorescence in situ hybridization (FISH) mapping

Mouse chromosomes were prepared from spleen cell culture or yolk sac epithelium and G-banded according to Seabright (1971). Bacterial artifical chromosome (BAC) clones of the RPCI-23 library (Osoegawa et al. 2000) were used as probes for FISH to chromosomes (Table 1). BACs were isolated by alkaline lysis (Birnboim and Doly 1979), labeled with biotin, and used in BAC FISH as described in detail in Traut et al. (2006). For chromosome painting we used the chr 1 and $\operatorname{chr} 8$ Star*FISH probes (Cambio, Cambridge, UK) according to the protocol of the manufacturer.

Morphologic inspection of homozygous translocation carriers

In a search for malformations in homozygous translocation carriers, two day-16 embryos (plug day = day 1), two
Table 1 RPCI-23 BAC clones from chrs 1 and 8

\begin{tabular}{|c|c|c|c|}
\hline Name & Position (Mb) & Labeled chr & Locus \\
\hline \multicolumn{4}{|l|}{ Chr 1} \\
\hline $132 \mathrm{a} 7$ & 95.3 & $1,1^{8}$ & $1 \mathrm{D}$ \\
\hline 70111 & 95.4 & $1,1^{8}$ & $1 \mathrm{D}$ \\
\hline $19 \mathrm{e} 22$ & 95.6 & $1,1^{8}$ & $1 \mathrm{D}$ \\
\hline $77 \mathrm{e} 14$ & 99.0 & $1,1^{8}$ & $1 \mathrm{E} 1$ \\
\hline $27 f 3$ & 101.2 & $1,1^{8}$ & $1 \mathrm{E} 1-2.1$ \\
\hline $202 \mathrm{a} 19$ & 101.4 & $1,1^{8}$ & $1 \mathrm{E} 2.1$ \\
\hline $217 \mathrm{j} 9$ & 101.6 & $1,1^{8}$ & $1 \mathrm{E} 2.1$ \\
\hline $472 \mathrm{i} 23$ & 101.7 & $1,1^{8}, 8^{1}$ & 1E2.1 \\
\hline $425 \mathrm{e} 13$ & 101.7 & $1,1^{8}, 8^{1}$ & 1E2.1 \\
\hline $365 \mathrm{~b} 12$ & 101.8 & $1,1^{8}, 8^{1}$ & $1 \mathrm{E} 2.1$ \\
\hline 350B3 & 102.9 & $1,8^{1}$ & $1 \mathrm{E} 2.1$ \\
\hline $84 \mathrm{~m} 14$ & 105.9 & $1,8^{1}$ & 1E2.1-2.2 \\
\hline $66 \mathrm{a} 20$ & 117.5 & $1,8^{1}$ & $1 \mathrm{E} 2.3$ \\
\hline $406 \mathrm{i} 13$ & 117.6 & $1,8^{1}$ & $1 \mathrm{E} 2.3$ \\
\hline \multicolumn{4}{|l|}{ Chr 8} \\
\hline $91 \mathrm{c} 5$ & 27.1 & $8,8^{1}$ & $8 \mathrm{~A} 4$ \\
\hline $7 \mathrm{e} 12$ & 28.5 & $8,8^{1}$ & $8 \mathrm{~A} 4$ \\
\hline $5 \mathrm{e} 5$ & 30.7 & $8,8^{1}$ & $8 \mathrm{~A} 4$ \\
\hline $98 \mathrm{i} 10$ & 31.9 & $8,8^{1}$ & 8A4-B1 \\
\hline $142 \mathrm{f} 11$ & 32.0 & $8,8^{1}$ & 8A4-B1 \\
\hline $325 b 24$ & 32.2 & $8,8^{1}$ & $8 \mathrm{~B} 1$ \\
\hline 19 n19 & 32.4 & $8,8^{1}$ & $8 \mathrm{~B} 1$ \\
\hline $11 \mathrm{p} 20$ & 32.6 & $8,8^{1}$ & $8 \mathrm{~B} 1$ \\
\hline $348 \mathrm{e} 10$ & 32.9 & $8,8^{1}$ & $8 \mathrm{~B} 1$ \\
\hline $74 \mathrm{~h} 12$ & 33.4 & $8,8^{1}$ & $8 \mathrm{~B} 1$ \\
\hline $355 f 14$ & 33.3 & $8,8^{1}, 1^{8}$ & $8 \mathrm{~B} 1$ \\
\hline $134 \mathrm{~d} 20$ & 33.6 & $8,1^{8}$ & $8 \mathrm{~B} 1$ \\
\hline $78 \mathrm{~g} 23$ & 34.2 & $8,1^{8}$ & $8 \mathrm{~B} 1$ \\
\hline $124 \mathrm{~h} 22$ & 42.1 & $8,1^{8}$ & $8 \mathrm{~B} 1$ \\
\hline $193 \mathrm{~h} 13$ & 48.3 & $8,1^{8}$ & $8 \mathrm{~B} 3$ \\
\hline
\end{tabular}

neonates, two pups of 2 days, one pup of 10 days, and one adult were dissected and examined under a dissecting microscope, fixed in Bouin's fluid, and stored in $70 \%$ ethanol. The brains of the two embryos and of two heterozygous siblings were further processed, dehydrated, and embedded in paraffin. Transverse serial sections of $5-\mu \mathrm{m}$ thickness were stained with hematoxylin-eosin and inspected for histologic abnormalities.

Isolation of RNA and genomic DNA

Total RNA was prepared with the Trizol (Invitrogen, Germany, Karlsruhe) method. First-strand cDNA was synthesized from total RNA using Superscript III (Invitrogen) reverse transcriptase. Isolation of genomic mouse 
DNA by phenol/chloroform extraction and Southern hybridization after alkaline DNA transfer to nylon membranes were performed by applying standard methods (Sambrook and Russell 2001).

\section{Genotyping}

For routine genotyping we used PCR with primers of microsatellite marker D1Mit157 (http://www.informatics. jax.org). D1Mit157 is located at position $\sim 101.4 \mathrm{Mb}$ on chr 1 , only $\sim 330 \mathrm{~kb}$ proximal to the breakpoint. A D1Mit157 allele of $\sim 160$ bp defined wild-type chr 1 , an allele of $\sim 180$ bp defined the translocation $\mathrm{chr} 1^{8}$. The karyotype was regularly checked with conventional cytogenetic techniques in the breeding colony. We never observed a discrepancy between PCR results and karyotyping for the discrimination of heterozygous and homozygous carriers of the translocation and wild-type mice.
PCR

PCR reactions giving rise to expected products of less than $1 \mathrm{~kb}$ were carried out with $T a q$ polymerase from Qiagen (Hilgen, Germany). Inverse PCRs (Ochman et al. 1990) were performed with the Expand kit from Roche (Mannheim, Germany). Prior to inverse PCR, the genomic template DNA was cut with a restriction enzyme and religated as specified in Results. PCR reactions were performed as follows: $95^{\circ} \mathrm{C}$ for $2 \mathrm{~min}$; ten cycles with $94^{\circ} \mathrm{C}$ for $15 \mathrm{sec}$, specific annealing temperature $T_{\mathrm{A}}$ (Table 2) (where $T_{\mathrm{A}}$ is decreased by $0.5^{\circ} \mathrm{C} /$ cycle) for $15 \mathrm{sec}$, and $72^{\circ} \mathrm{C}$ (Qiagen $\mathrm{Taq}$ polymerase) or $68^{\circ} \mathrm{C}$ (Expand) for extension time $t$ (in minutes) (see Table 2); 30 cycles with $94^{\circ} \mathrm{C}$ for $15 \mathrm{sec},\left(T_{\mathrm{A}}-5\right)^{\circ} \mathrm{C}$ for $15 \mathrm{sec}, 72^{\circ} \mathrm{C}$ or $68^{\circ} \mathrm{C}$ for $t$ min, and $72^{\circ} \mathrm{C}$ for $2 \mathrm{~min}$ or $68^{\circ} \mathrm{C}$ for $5 \mathrm{~min}$.

Reverse transcriptase (RT)-PCR reactions for monitoring expression of Caspr5-1, Caspr5-2, and Caspr5-3 were performed as described (Traut et al. 2006), using primers

Table 2 PCR primers, specific annealing temperatures $\left(T_{\mathrm{A}}\right)$, and extension times $(t)$

\begin{tabular}{|c|c|c|c|c|}
\hline Name & $5^{\prime}-3^{\prime}$ sequence & Chr: position & $T_{\mathrm{A}}\left({ }^{\circ} \mathrm{C}\right)$ & $t(\min )$ \\
\hline $\mathrm{C} 1 \mathrm{~F} 1$ & AACTCTGAGTTTGCGGGTACCTC & 1: 101778363-101778385 & 60 & 13 \\
\hline $\mathrm{C} 1 \mathrm{~B} 1$ & GGAACTAGAGAATGGGCAAGTGG & 1: 101768061-101768083 & & \\
\hline $\mathrm{C} 1 \mathrm{~F} 1$ & AACTCTGAGTTTGCGGGTACCTC & 1: 101778361-101778385 & 59 & 3 \\
\hline C1B6 & AAAAGAAAACACTTAGCCCATCC & 1: 101775555-101775578 & & \\
\hline $\mathrm{C} 1 \mathrm{~F} 10$ & TGAGAGTAGAGTTATCTTCCCTG & 1: 101772010-101772032 & 56 & 1 \\
\hline $\mathrm{C} 1 \mathrm{~B} 12$ & AGATCTGCTTACATTCCACTGC & 1: 101771451-101771472 & & \\
\hline $\mathrm{C} 1 \mathrm{~F} 11$ & CATGGACACATATATGCTTCCTGG & 1: 101776440-101776463 & 61 & 7 \\
\hline C1B14 & CAGATAGACGGAATGGGCAATG & 1: $101777862-101777883$ & & \\
\hline $\mathrm{C} 1 \mathrm{~F} 12$ & GTCTCTTCACATTAGCTGCCCAG & 1: 101776286-101776308 & 60 & 7 \\
\hline $\mathrm{C} 1 \mathrm{~B} 15$ & GCAATGAGGTAAAGGAGGCACC & 1: 101777877-101777899 & & \\
\hline $\mathrm{C} 1 \mathrm{~F} 14$ & GACTGGGCAATATTGTTCCAAAT & 1: 101773716-101773738 & 61 & 8 \\
\hline $\mathrm{C} 1 \mathrm{~B} 17$ & GCAGTTGGGGACACAAAATAGAT & 1: 101774300-101774322 & & \\
\hline $\mathrm{C} 1 \mathrm{~F} 13$ & CCAAACCAGGAAATGATCAGAGTT & 1: $101773443-101773466$ & 61 & 6 \\
\hline C1B6 & AAAAGAAAACACTTAGCCCATCC & 1: 101775556-101775578 & & \\
\hline BPF1 & CTTTATATGTATAAGGTGGGGTG & 1: 116939941-116939963 & 52 & 10 \\
\hline BPB1 & GAATGTGATTCTTAAACTCTTCC & 1: 116940256-116940278 & & \\
\hline BPF2 & GTATTATATTTCTTTAACCATACC & 1: 116939758-116939781 & 51 & 5 \\
\hline BPB2 & TTCCATGATTCCATTTATGTAGG & 1: 116940308-116940330 & & \\
\hline $\mathrm{C} 8 \mathrm{~F} 4$ & GTATGCCCTGACAGTATCATCTCTAA & 8: $33248839-33248864$ & 59.5 & 5 \\
\hline $\mathrm{C} 8 \mathrm{~B} 2$ & CTGGGACAGGATTTCAAATGTTG & 8: 33249117-33249139 & & \\
\hline C8F5 & CCTGGGCTCTGATTTTCAGTGTA & 8: $33248664-33248686$ & 55.5 & 4.5 \\
\hline C8B3 & CCAAATCCTGTAGCTTGCTATAA & 8: $33249151-33249173$ & & \\
\hline
\end{tabular}


Table 3 Antisense oligonucleotide probes for transcript mapping

\begin{tabular}{lll}
\hline Name & Sequence & Exon \\
\hline Caspr5-1 is1 & CAGGATGACCAAGGGCACAGTGCTGCTGAGCCGAGCTTTCCT & 6 \\
Caspr5-1 is2 & AAATCTGTATTCGGGAGGTGTCTGGAGCTGGGGAAGCAGCAT & 9 \\
Caspr5-2 is1 & CAGAATGGCTGAGGGTGTAATACTACTGAGGCGGGCTTTGCT & 6 \\
Caspr5-2 is2 & ATATCTGTAGCCAGGGGGTTTCCAGAGCTGGAGAAGCAGGAT & 9 \\
Caspr5-2 is3 & AACCAGTATCGTTTGACATCTCCAGGCAGCTCTCCTCTAGGC & $14-15$ \\
Caspr5-3 is1 & CAGAGTTGCCAAGGGTGCAGTGCTGCTGACCTGGGCTTTGCT & 6 \\
Caspr5-3 is2 & ATATCTGCAGCCAGGAGGTGTCTGGAGGCAGGGATGCAGCAT & 9 \\
\hline
\end{tabular}

from exon 1 and exon 3 of each gene. $\beta$-actin was amplified as internal control.

\section{Radioactive in situ hybridization}

The distribution of Caspr5-1, Caspr5-2, and Caspr5-3 mRNA was analyzed by radioactive in situ hybridization on sections from embryonic and adult NMRI mice. Day16 embryos and dissected adult brains were frozen on dry ice and subsequently cut using a microtome cryostat $(16 \mu \mathrm{m})$. For hybridization with the different Caspr5 mRNAs, antisense oligonucleotide probes (Table 3) were used, applying conditions described previously (Wisden and Morris 1994).

Briefly, the oligonucleotides were $3^{\prime}$-end-labeled using terminal deoxynucleotidyl transferase and $\left[(\alpha){ }^{35} \mathrm{~S}\right]$ dATP. Sections were hybridized in $50 \%$ formamide, $4 \times$ SSC (0.6 M NaCl, $0.06 \mathrm{M}$ sodium citrate), $10 \%$ dextran, and
$1 \mathrm{pg} / \mu \mathrm{l}$ labeled oligonucleotide at $42^{\circ} \mathrm{C}$ overnight and subsequently washed at $55^{\circ} \mathrm{C}$ for $30 \mathrm{~min}$, dehydrated, and exposed to $\operatorname{Kodak}^{\circledR}$ BioMax MR film. The different oligonucleotides chosen for each Caspr5 gene gave qualitatively similar results.

\section{Results}

Cytogenetic characterization of a novel translocation

In a mouse line carrying the Robertsonian translocation $\mathrm{Rb}(1.18) 10 \mathrm{Rma}$ with the genetic background of outbred strain NMRI, we detected a spontaneous reciprocal translocation between chr 1 and chr 8 . The translocation was associated with reduced fertility. The breakpoints were cytogenetically mapped in G-banded chromosomes to bands 1E2.1 and 8B1.2 (Fig. 1).

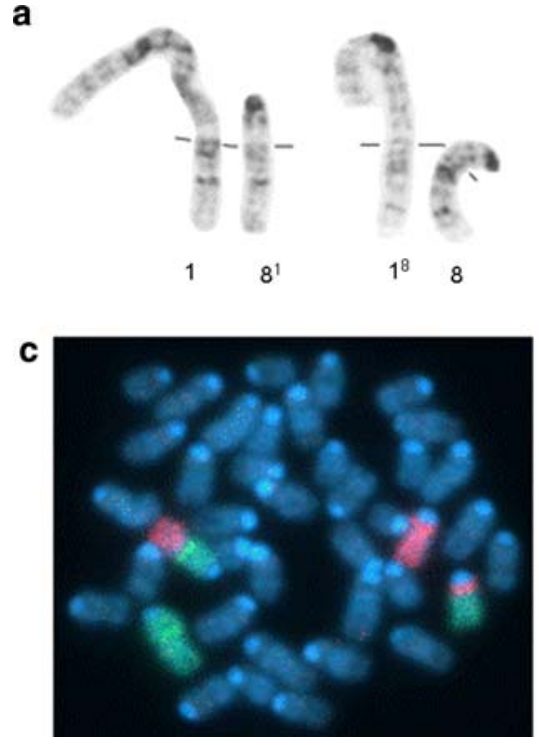

Fig. 1 Reciprocal $\mathrm{T}(1 ; 8)$ translocation in G-banded chromosomes. a Chr 1 , chr 8 , and the translocation chrs $1^{8}$ and $8^{1}$ of a heterozygous animal. Identification of chrs 1 and $1^{8}$ was facilitated through the Robertsonian marker chr $\mathrm{Rb}(1 ; 18) 10 \mathrm{Rma}$. Lines indicate positions of breakage and fusion. Note the identical band patterns below the lines

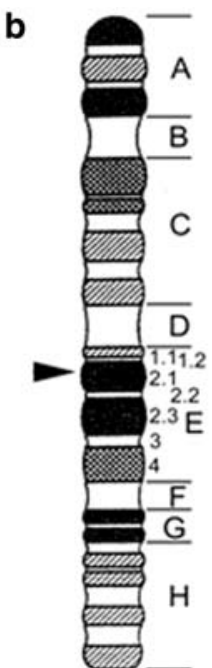

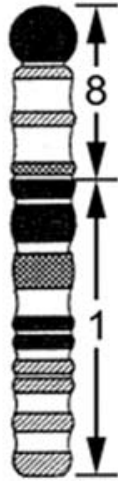

$8^{1}$

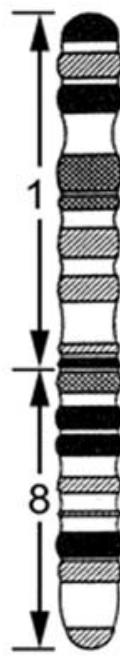

$1^{8}$

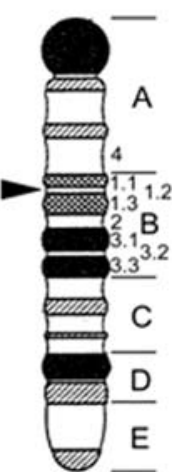

of 1 and $8^{1}$ on the one hand and $1^{8}$ and 8 on the other hand. b Schematic drawing of the G-banded chrs. Arrows indicate positions of breakage and fusion. $\mathbf{c}$ Highlighting of translocation $\mathrm{chr} 1^{8}$ and $\mathrm{chr}$ $8^{1}$ by chromosome painting using painting probes specific for chr 1 (green) and chr 8 (red) 

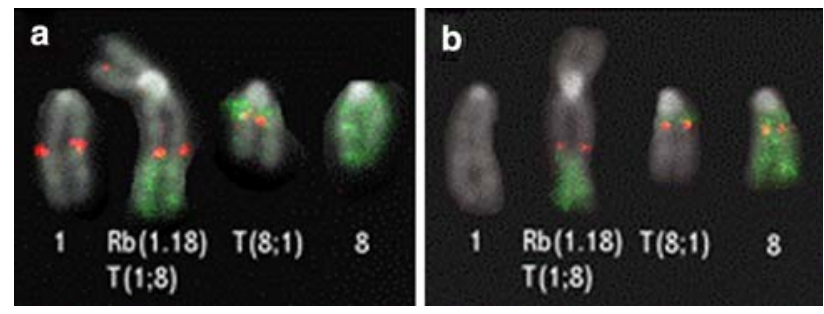

Fig. 2 FISH with BACs from the breakpoint regions of mouse chr 1 and chr 8. a BAC clone RP23-425e13 on chr 1. b BAC clone RP23$355 \mathrm{f} 14$ on chr 8. Partial karyotypes of $\mathrm{F}_{1}$ hybrids between NMRI and $\mathrm{Rb}(1.18) 10 \mathrm{RmaT}(\mathrm{Tp}(1 \mathrm{E} 2.1) ; 8 \mathrm{~B} 1.2) 2 \mathrm{Lub}$ are shown. FISH signals in red, chr 8 painting in green. Chromosomes were stained with DAPI

\section{Mapping of the breakpoints by BAC FISH}

We performed FISH using BAC clones of the RPCI-23 library (Osoegawa et al. 2000) as probes to successively narrow in on the location of the breakpoints. The BACs were selected from both breakpoint regions, exploiting the BACs' map positions in ENSEMBL Mouse Contigview ( http://www.ensembl.org/Mus_musculus/contigview) and our cytogenetic results (Table 1).

In principle, two FISH signals of a chr $1 \mathrm{BAC}$, one signal each on chr 1 and on derivative chr $1^{8}$, marked locations proximal to the breakpoint, while signals on chr 1 and $\operatorname{chr} 8^{1}$ marked locations distal to the breakpoint. Three signals, on $\operatorname{chr} 1, \operatorname{chr} 1^{8}$, and $\operatorname{chr} 8^{1}$, identified a breakpointspanning BAC of chr 1 . Likewise, signals of chr 8 BACs on chr 8 and chr $8^{1}$, on chr 8 and chr $1^{8}$, or on chr $8, \operatorname{chr} 1^{8}$, and chr $8^{1}$, marked proximal, distal, and breakpoint-spanning locations, respectively, of chr 8 .

Using this strategy, we ended up with four RP23-BACs, 472i23, 425e13, 448n16, and 408d6, which all labeled chr 1 and both translocation chromosomes $1^{8}$ and $8^{1}$ (Fig. 2a) and, hence, spanned the breakpoint on chr 1 . We mapped the BACs cytogenetically to band 1E2.1 in accordance with our cytogenetic characterization of the breakpoint. The complete sequence of the BACs could be deduced from the end sequences derived from the TIGR BAC end-sequencing database (http://www.tigr.org/tdb/bac_ends/mouse/bac end_intro.html) and Celera contig GA_x6K02T2R7CC, which was identified by BLAST searches using the end sequences as queries. They were $\sim 180-220 \mathrm{~kb}$ in size and had been mapped to position $\sim 101.7 \mathrm{Mb}$ according to ENSEMBL release 48, NCBI Build 37.1. The chr 1 breakpoint, therefore, maps close to position $101.7 \mathrm{Mb}$.

BAC RP23-355f14, which carried an insert of $\sim 220 \mathrm{~kb}$, labeled chr $8, \operatorname{chr} 1^{8}$, and chr $8^{1}$ (Fig. 2b). Hence, this BAC spanned the breakpoint of chr 8 . We mapped the BAC to chr band 8B1.2 and, thus, confirmed the cytogenetic position of the chr 8 breakpoint. According to ENSEMBL, the BAC maps to position $\sim 33.3 \mathrm{Mb}$ in the chr 8 contig.
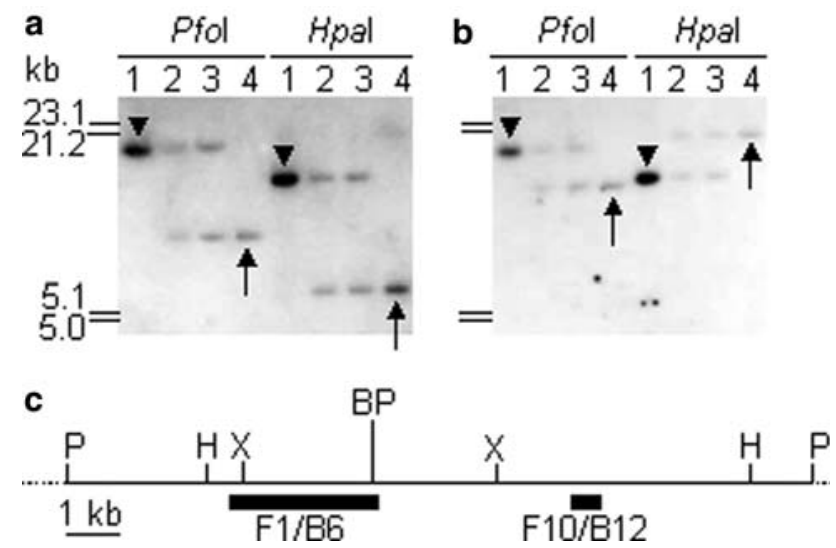

Fig. 3 Southern hybridizations with probes from the immediate vicinity of the breakpoint on chr 1 . Genomic DNAs of a wild-type NMRI animal (lanes 1), a homozygous $\mathrm{T}(1 ; 8)$ animal (lanes 4), and two heterozygous offspring (lanes 2 and 3) were digested with $P f o \mathrm{I}$ and HpaI, gel-separated, and blotted. a Hybridization with PCRgenerated probe $\mathrm{C} 1 \mathrm{~F} 1 / \mathrm{C} 1 \mathrm{~B} 6$ (F1/B6). b Hybridization with probe C1F10/C1B12 (F10/B12). Arrowheads point to signals derived from the wild-type animal; arrows point to signals derived from the homozygous $\mathrm{T}(1 ; 8)$ animal. Note that the signals from the wild-type chr 1 are at the same position in (a) and (b), while the signals from the homozygous $\mathrm{T}(1 ; 8)$ animal are at different positions in (a) and (b). This indicates that the breakpoint on chr 1 must be located between the two probes. $c$ Partial restriction map and location of probes F1/B6 and F10/B12 in the breakpoint region of wild-type chr 1 at position 101.775 Mb. $\mathrm{BP}=$ breakpoint; $\mathrm{H}=H p a \mathrm{I}, \mathrm{P}=$ PfoI, $\mathrm{X}=$ XbaI

Molecular mapping of the breakpoints

To narrow in on the position of the breakpoint in chr 1, we generated smaller FISH probes from various regions of BAC RP23-425e13 by PCR. Depending on the position of these probes in RP23-425e13, they labeled either $1^{8}$ or $8^{1}$, confirming that this BAC spanned the breakpoint on chr 1 . A probe of $\sim 10.3 \mathrm{~kb}$, defined by primers $\mathrm{C} 1 \mathrm{~F} 1 / \mathrm{C} 1 \mathrm{~B} 1$ (Table 2), labeled both $1^{8}$ and $8^{1}$, indicating that this fragment spanned the breakpoint.

With Southern hybridizations, two subfragments used as probes detected restriction fragment length differences between genomic DNAs of a translocation homozygote and a wild-type animal. The two probes marked the same fragment in the wild-type animal (Fig. 3a, b, lanes 1), but a different-sized fragment in the translocation homozygote (Fig. 3a, b, lanes 4), while both fragments were marked in heterozygotes (compare Fig. 3a, b, lanes 2 and 3). We deduced that the breakpoint was located in the $\sim 4-\mathrm{kb}$ genomic interval between the two probes.

To identify the breakpoints at the nucleotide level, we applied inverse polymerase chain reaction (inverse PCR). $X b a \mathrm{I}$ digested and re-ligated genomic DNA of a translocation homozygote served as template. With the nested primer pairs $\mathrm{C} 1 \mathrm{~F} 14 / \mathrm{C} 1 \mathrm{~B} 17$ and C1F13/C1B6 of chr 1 (Table 2), we amplified an $\sim 4.5$-kb fragment. It contained 


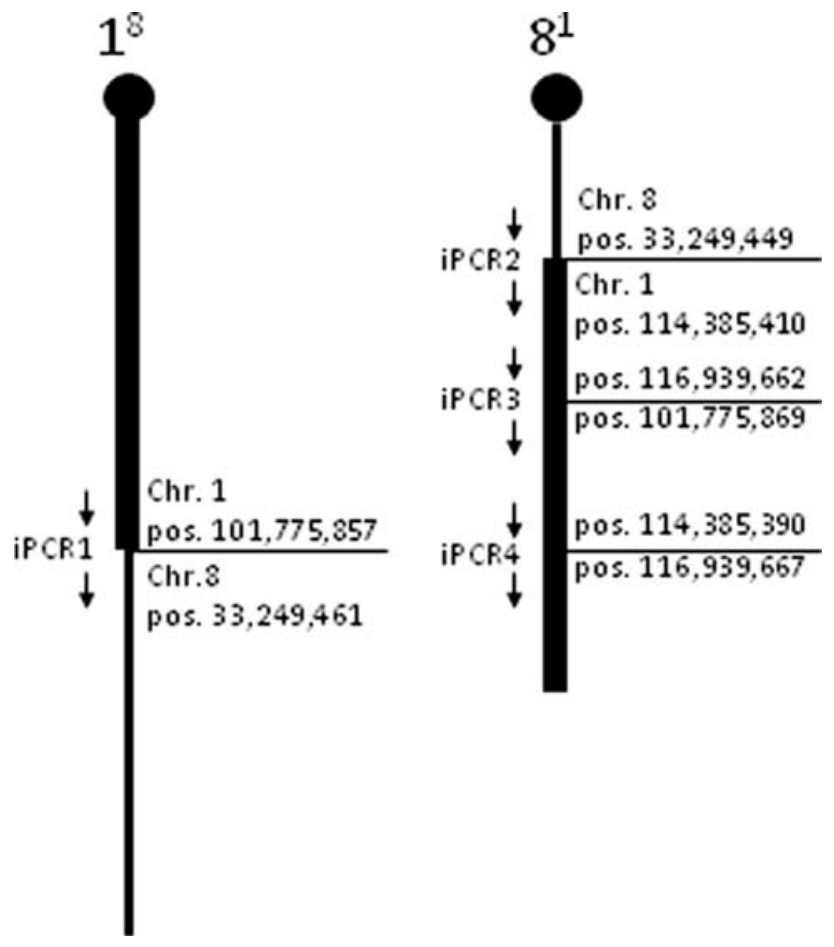

Fig. 4 Reconstruction of $\operatorname{chr} 1^{8}$ and $\operatorname{chr} 8^{1}$. Chr 1, thick line, chr 8 , thin line. Breakpoint positions revealed by inverse PCR (iPCR) experiments $1-4$ are given in base pairs. The directions of the fused sequences are indicated by arrows

expected sequences from the $\sim 101.8-\mathrm{Mb}$ region of chr 1 at its ends and a sequence of $\sim 4.1 \mathrm{~kb}$ which mapped to position $\sim 33.2 \mathrm{Mb}$ of $\mathrm{chr} 8$ (GenBank accession Nos. DQ870779 and DQ870780). The sequence of the PCR product mapped the fusion to position $101,775,857$ of the chr 1 sequence and to position 33,249,461 of the chr 8 sequence, with one extra base, $\mathrm{T}$, in between (reference: NCBI Build 37.1). The $5^{\prime}-3^{\prime}$ directions of the fused sequences relative to each other and to the centromeres of chr 1 and chr 8 proved to be in accordance with the expected directions (Fig. 4, iPCR1).

Knowledge of the $1^{8}$ fusion sequence helped to determine the chr 8 breakpoint. We defined and used the nested primer pairs $\mathrm{C} 8 \mathrm{~F} 4 / \mathrm{C} 8 \mathrm{~B} 2$ and $\mathrm{C} 8 \mathrm{~F} 5 / \mathrm{C} 8 \mathrm{~B} 3$ (Table 2) from the chr 8 sequence proximal of the breakpoint for inverse PCR. TaqI-digested and re-ligated genomic DNA of the translocation homozygote was used as template. The PCR product of $\sim 3 \mathrm{~kb}$ contained sequences from chr 1 and $\mathrm{chr}$ 8 (accession Nos. DQ870781 and DQ870782). The chr 8 sequence terminated at position $33,249,449$, which was $12 \mathrm{bp}$ proximal to the chr 8 breakpoint identified before, revealing the loss of $11 \mathrm{bp}$, CATAGGAAATA, by the translocation event. Surprisingly, the remaining sequence of $\sim 1.5 \mathrm{~kb}$ did not map to the $\sim 101.8-\mathrm{Mb}$ region of $\mathrm{chr}$ 1 , but started $\sim 13 \mathrm{Mb}$ downstream, at position $114,385,410$. In the $8^{1}$ fusion, therefore, the chr 1 and chr 8 sequences are joined at positions $114,385,410$ and 33,249,449, respectively (Fig. 4, iPCR2).

Our FISH results were not consistent with a gap of $\sim 13 \mathrm{Mb}$ in the $8^{1}$ fusion region (see Table 1). Two more inverse PCRs, however, detected the missing segment as an insertion just $\sim 2.6 \mathrm{Mb}$ distal to the $8^{1}$ fusion, and consequently in accordance with the resolving power of FISH.

Nested primer pairs C1F11/C1B14 and C1F12/C1B15 (Table 2) were defined from the $101.8-\mathrm{Mb}$ region of chr 1 , just across the breakpoint, and the same re-ligated DNA as in the first inverse PCR was used as template. We amplified an $\sim 5.5$-kb fragment containing a sequence of $\sim 4.7 \mathrm{~kb}$ which mapped to the $\sim 116.9-\mathrm{Mb}$ region on chr 1 (accession Nos. DQ870777 and DQ70778). This PCR product revealed the fusion of $\mathrm{chr} 1$ sequences at positions $101,775,869$ and $116,939,662$, having a T/A bp in common. Moreover, by comparison with the breakpoint position in translocation chr $1^{8}$, we recognized the loss of $11 \mathrm{bp}$, GTAGTTTTTTG (Fig. 4, iPCR3).

We used nested primer pairs BPF1/ BPB1 and BPF2/ BPB2 from the $\sim 116.9-\mathrm{Mb}$ region (Table 2) on BamHIdigested and re-ligated DNA of the translocation homozygote and obtained a product of $\sim 3 \mathrm{~kb}$ in which two sequences of chr 1 were fused at positions 114,385,390 and $116,939,667$, having a T/A bp in common (accession Nos. DQ870783 and DQ870784). Compared to the products of the second and third inverse PCR, we recognized the loss of $19 \mathrm{bp}$, TACAGGAATAAAATAACAA, in the 114.4$\mathrm{Mb}$ region and the loss of $4 \mathrm{bp}$, ATGC, in the $116.9-\mathrm{Mb}$ region (Fig. 4, iPCR4).

The complete reconstruction of the translocation chromosomes, including the three breakpoints in the chr 1 sequence and one breakpoint in chr 8, is shown in Fig. 4 . The description of the reciprocal translocation has been submitted to the Mouse Genome Database under the designation $\mathrm{T}(\mathrm{Tp}(1 \mathrm{E} 2.1) ; 8 \mathrm{~B} 1.2) 2 \mathrm{Lub}$ (MGI:3628904).

Disruption of the Caspr5-2 gene

We screened the ENSEMBL database for genes that might have been affected by the four breakage events. The rather large Caspr5-2 gene (accession No. BN000866) was identified to include position $101,775,857$, the most proximal chr 1 breakpoint. Caspr5-2 covers about $712 \mathrm{~kb}$ on chr 1, from approximately 101.7 to $102.4 \mathrm{Mb}$. The coding region of Caspr5-2 consists of 24 exons and encodes a putative transmembrane protein of 1292 amino acids which belongs to the neurexin superfamily (Traut et al. 2006). A BLAST search with the cDNA sequence of Caspr5-2 revealed that the first coding exon at positions 101,669,342-101,669,423 maps proximal to the breakpoint, while all other exons map distally. Accordingly, Caspr5-2 was disrupted between the 


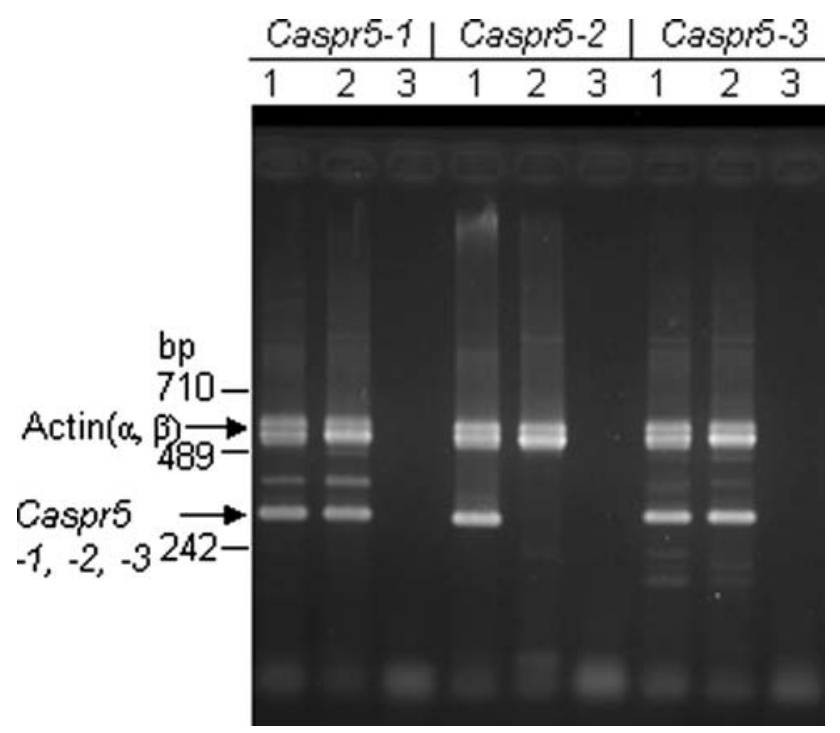

Fig. 5 RT-PCR with RNA from brain and specific primers from exon 1 and exon 3 of Caspr 5-1, Caspr5-2, and Caspr5-3, respectively. $1=$ wild-type animal; $2=\mathrm{T}(1 ; 8)$ homozygote; $3=$ mock control. Coamplification of actin cDNA was used as internal control

first two coding exons, with the first exon left on $1^{8}$ and the remaining exons translocated to $8^{1}$.

We confirmed abrogation of Caspr $5-2$ expression in a homozygous $\mathrm{T}(1 ; 8)$ animal by RT-PCR, using primers from exon 1 and exon 3 and RNA from adult brain, where Caspr5-2 is highly expressed (Traut et al. 2006). No product was obtained, whereas a wild-type control gave rise to a cDNA product of the expected size (Fig. 5). Control RT-PCRs using primers from exon 1 and exon 3 of Caspr5-2 paralogs Caspr5-1 and Caspr5-3, which are also expressed in brain, gave rise to cDNA products in both animals (see Fig. 5). The RT-PCR data accordingly confirmed that the translocation resulted in a Caspr5-2 null allele.

No gene is known or predicted in the close vicinity of the three other breakpoints, at chr 1 positions $114.39 \mathrm{Mb}$ and $116.94 \mathrm{Mb}$ and chr 8 position $33.25 \mathrm{Mb}$. This makes disruption of or aberrant fusion with another gene unlikely, even though it cannot be completely excluded. Accordingly, Caspr $5-2$ is the prime candidate to have caused the phenotype, perinatal lethality, in translocation homozygotes (see below).

Perinatal lethality

Heterozygous translocation carriers $(+/ \mathrm{T}$ or $\mathrm{Rb}+/ \mathrm{Rb} \mathrm{T})$ were crossed with either wild-type animals $(+/+)$ or heterozygous translocation carriers $(+/ \mathrm{T}$ or $\mathrm{Rb}+/ \mathrm{Rb} \mathrm{T})$. Segregation of $+/+$ and $+/ \mathrm{T}$ genotypes was in accordance with expectation in all crosses (Table 4). There was, however, a drastic underrepresentation of T/T animals $\left(\chi^{2}\right.$ test, $p<0,001)$ when the genotypes were assessed later, 56 weeks after birth. Only a few homozygous T/T animals survived this period in $+/ \mathrm{T} \times+/ \mathrm{T}$ crosses but none in the $\mathrm{Rb}+/ \mathrm{Rb} \mathrm{T} \times \mathrm{Rb}+/ \mathrm{Rb} \mathrm{T}$ crosses (compare Table 4, lines 4 and 5). The difference (Fischer's exact test, $0.01>p>0,001)$ probably reflects an influence of the genetic background [NMRI vs. $\mathrm{Rb}(1.18) 10 \mathrm{Rma}$ ] on survival of the homozygotes.

The few surviving homozygous translocation carriers from $+/ \mathrm{T} \times+/ \mathrm{T}$ crosses did not transmit viability to their offspring in backcrosses with heterozygous $+/ \mathrm{T}$ animals. When offspring of these crosses were genotyped at birth or earlier, there was again no significant deviation from the expected ratios (Table 4, lines 6 and 7) but drastic underrepresentation of T/T animals when genotyped 5-6 weeks later (Table 4 , line $8 ; \chi^{2}$ test, $p<0,001$ ).

Note that the expected segregation ratio in $+/ \mathrm{T} \times+/ \mathrm{T}$ crosses is not the Mendelian 1:2:1 but 1:4:1. This is so because the two differently imbalanced gametes, e.g., $1+1^{8}$ and $8+8^{1}$, join to give a balanced zygote, $1+8+1^{8}+8^{1}$. According to the Mouse imprinting map (Beechey et al. 2004), chr 1 and chr 8 have no imprinted regions and, hence, these zygotes are expected to be viable.

Table 4 Distribution of genotypes among offspring of translocation carriers

\begin{tabular}{lllllll}
\hline$\#$ & Crosses & Offspring & & & Expected ratio & Stage of development \\
\cline { 3 - 6 } & Female $\times$ male & $+/+$ & $+/ \mathrm{T}$ & $\mathrm{T} / \mathrm{T}$ & & At birth \\
\hline 1 & $+/ \mathrm{T} \times+/+$ & 30 & 24 & - & $1: 1$ & At birth \\
2 & $+/+\times+/ \mathrm{T}$ & 102 & 90 & - & $1: 1$ & At birth \\
3 & $+/ \mathrm{T} \times+/ \mathrm{T}$ & 11 & 65 & 11 & $1: 4: 1$ & $5-6$ weeks after birth \\
4 & $+/ \mathrm{T} \times+/ \mathrm{T}$ & 90 & 349 & 17 & $1: 4: 1^{\mathrm{a}}$ & $5-6$ weeks after birth \\
5 & $\mathrm{Rb}+/ \mathrm{Rb} \mathrm{T} \times \mathrm{Rb}+/ \mathrm{Rb} \mathrm{T}$ & 49 & 150 & 0 & $1: 4: 1^{\mathrm{a}}$ & Day 10.5-18.5 of pregnancy \\
6 & $+/ \mathrm{T} \times \mathrm{T} / \mathrm{T}$ & - & 27 & 24 & $1: 1$ & At birth \\
7 & $+/ \mathrm{T} \times \mathrm{T} / \mathrm{T}$ & - & 75 & 74 & $1: 1$ & $5-6$ weeks after birth \\
8 & $+/ \mathrm{T} \times \mathrm{T} / \mathrm{T}$ & - & 279 & 35 & $1: 1^{\mathrm{a}}$ & 5
\end{tabular}

${ }^{a} p<0.001$ when results and expectation are compared in $\chi^{2}$ test 

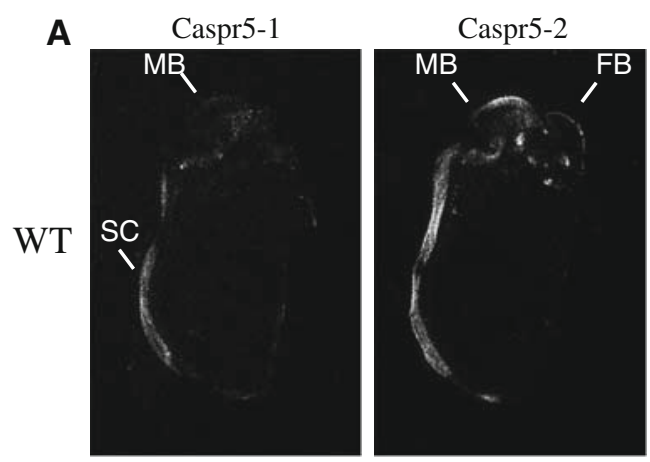

\section{Caspr5-3}
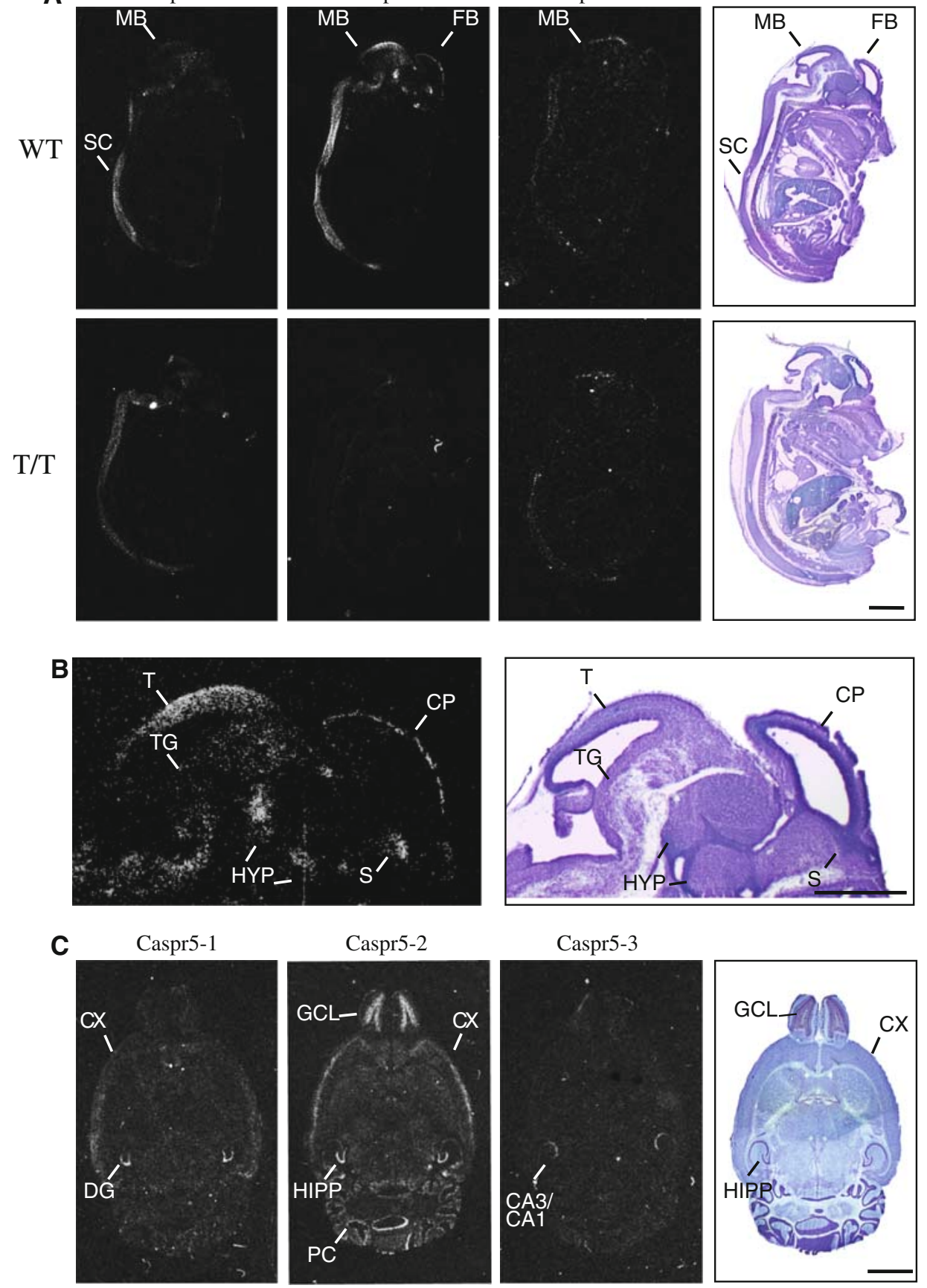

\section{Caspr5-2}

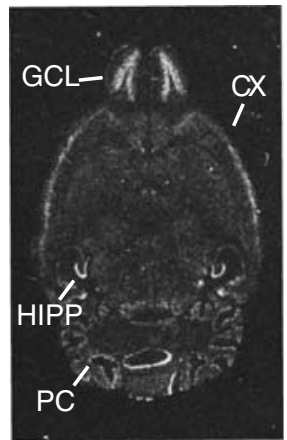

Caspr5-3
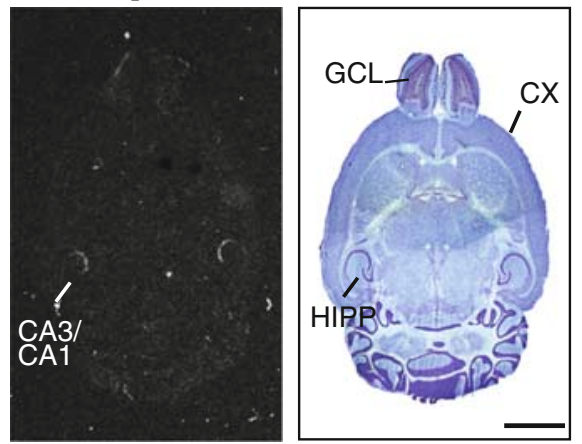

This was confirmed by our segregation data in the relevant crosses. We found $150+/+$ and $564+/ \mathrm{T}$ animals (total of Table 4 , lines 3, 4, and 5) when $143+/+$ and $571+/ \mathrm{T}$ were expected.

\section{Expression mapping of Caspr5 genes}

We had shown previously by RT-PCR that the three mouse Caspr 5 genes displayed tissue-specific and largely overlapping expression patterns (Traut et al. 2006). To analyze the expression patterns of the Caspr 5 genes at higher resolution, we performed in situ hybridization experiments using gene-specific oligonucleotide probes in wild-type and homozygous T/T embryos at day 16 as well as in brains of adult wild-type animals (Table 3 and Fig. 6). At embryonic day 16, expression of all three Caspr5 genes was restricted to the central nervous system. In wild-type embryos, Caspr5-2 showed strongest expression in the cortical plate of the developing forebrain, tectum, hypothalamus, and septum and weaker expression in hippocampus, 
4 Fig. 6 In situ hybridization of Caspr5 genes in wild-type and T/T mice. a Expression of Caspr 5 genes in wild-type sagittal sections of 16-day-old embryos. All three Caspr 5 genes are expressed in the midbrain and the spinal cord. Caspr5-2 is strongly expressed in forebrain and future neocortex. Note that in $\mathrm{T} / \mathrm{T}$ embryos, the expression of Caspr5-1 and Caspr5-3 is unchanged, while Caspr5-2 expression is absent. b Higher magnification of the head area shown in a revealing Caspr5-2 expression in the cortical plate of the neocortex, the differentiating fields of the septum, and the hypothalamus as well as in the tectum and the tegmentum of the midbrain and in the medulla. c Expression of the Caspr 5 genes in wild-type adult brain (horizontal sections). Caspr5-1 is strongly expressed in the dentate gyrus of the hippocampus and, more weakly, throughout all cortical layers. Casp5-3 expression is detected only in the CA1/CA3 area of the hippocampus. Caspr 5-2 shows the most widespread and highest expression, particularly in the granule cell layer of the olfactory bulb, in cortical layers $2 / 3$, in the three major subregions of the hippocampus, and in the Purkinje cell layer of the cerebellum. Right panels: To facilitate orientation, representative sections (those hybridized with the Caspr5-2 probes) were counterstained using standard Nissl (cresyl violet) staining. Corresponding sections hybridized with the different probes were obtained from the same tissue sample at a $50-\mu \mathrm{m}$ distance. Scale bars $=2.5 \mathrm{~mm} . \mathrm{MB}=$ midbrain; $\mathrm{SC}=$ spinal cord $; \mathrm{FB}=$ forebrain; $\mathrm{T}=$ tectum; $\mathrm{TG}=$ tegmentum; $\mathrm{CP}=$ cortical plate; $\mathrm{HYP}=$ differentiating field of the hypothalamus; $\mathrm{S}=$ differentiating field of the septum; $\mathrm{CX}=$ neocortex; $\mathrm{DG}=$ dentate gyrus of the hippocampus; $\mathrm{GCL}=$ granule cell layer; $\mathrm{HIPP}=$ hippocampus; $\mathrm{PC}=$ Purkinje cell layer; $\mathrm{CA} 1$ / $\mathrm{CA} 3=\mathrm{CA} 1$ and CA3 subregion of the hippocampus

tegmentum, isthmus, medulla, and spinal cord. In accordance with our previous expression studies, we did not detect Caspr5-2 expression in homozygous T/T embryos.

Expression of Caspr5-1 was restricted to midbrain, hindbrain, and spinal cord in both wild-type and homozygous T/T embryos. Caspr5-3 appeared to be weakly expressed in the whole central nervous system of embryos from both genotypes.

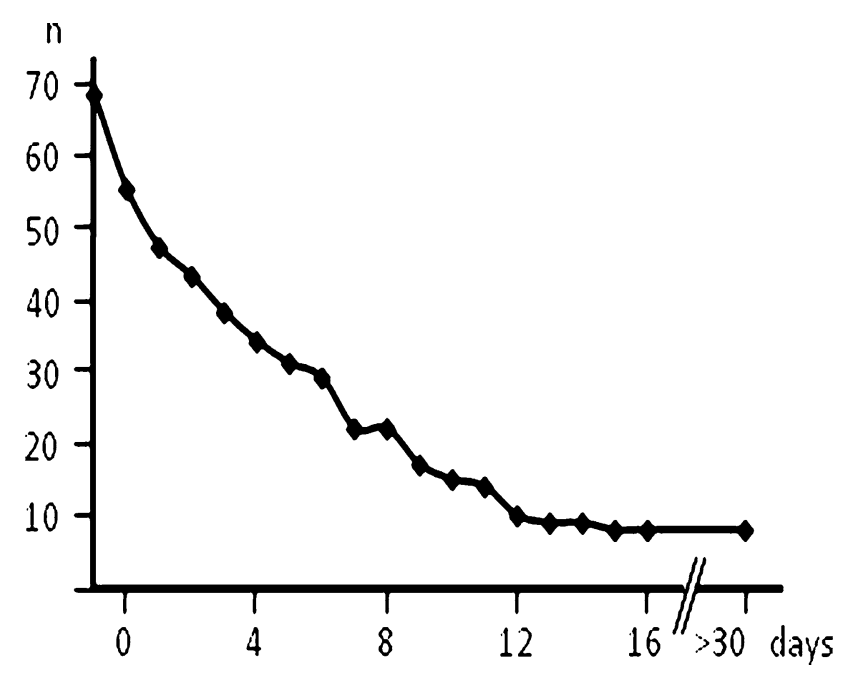

Fig. 7 Survival curve of a sample of $68 \mathrm{~T} / \mathrm{T}$ individuals. Day 0 is the day of birth. 13 individuals were stillborn
Because embryonic expression of the three Caspr5 genes was restricted to the central nervous system, we confined our analysis in an adult wild-type animal to the brain. Caspr5-2 was highly expressed in the granule cell layer and the periglomerular layer of the olfactory bulb, in the principal cell layers of the hippocampal formation, in cortical layers $2 / 3$, and in the Purkinje cells of the cerebellum. Weaker expression was found in all other cortical layers, striatum, and thalamus. Caspr5-1 was expressed mainly in the dentate gyrus of the hippocampus and all cortical layers. Expression of Caspr5-3 in the adult brain was restricted to the pyramidal layer in the CA1-3 area of the hippocampus.

Taken together, Caspr5-2 showed the highest and most widespread expression of the three Caspr5 genes in the embryonic and adult mouse.

\section{Search for abnormalities in T/T mice}

Few T/T individuals survived until adulthood; most died in the span of development from around birth up to 2 weeks after birth (Fig. 7). Most showed growth retardation before death. There was, however, considerable variation among individuals. We studied growth development in a sample of 12 newborn T/T carriers and $9 \mathrm{~T} /+$ sibs as controls (Table 5). One individual, T/T-12 in Table 5, showed no growth retardation at all and it survived until adulthood. Two others, T/T-10 and -11 , displayed growth retardation on day 5-6, but they also recovered and reached adulthood. The others died on different days within the first 2 weeks with or without visible growth retardation. Five of the dead bodies were dissected; all of them had milk in their stomachs; they had obviously been fed until shortly before death.

T/T animals were examined for morphologic abnormalities that could be associated with lethality. The sample included two embryos (day 16), two neonates, three pups (two of 2 days, one of 10 days), and an adult. The inspection of whole embryos and animals with respect to head, neck, back, and legs revealed no obvious difference between homozygous $\mathrm{T} / \mathrm{T}$ and heterozygous $+/ \mathrm{T}$ control animals. Moreover, no difference could be observed in thoracic and abdominal organs and complete brains. We particularly scrutinized the central nervous system where Caspr5-2 is mainly expressed. One of the 2-day pups and the 10-day pup showed severe growth retardation and were obviously moribund, but none displayed malformations of outer and inner organs.

Microscopic examination of hematoxylin-eosin-stained serial sections of brains from the day-16 embryos provided no obvious differences between heterozygous and homozygous siblings: all regions of the brains appeared to be unaltered. 
Table 5 Growth development of 12 newborn T/T individuals (T/T-1 to T/T-12) from day 1 until death (marked †)

\begin{tabular}{|c|c|c|c|c|c|c|c|c|c|c|c|c|c|c|c|c|}
\hline & \multicolumn{16}{|c|}{ Day } \\
\hline & 1 & 2 & 3 & 4 & 5 & 6 & 7 & 8 & 9 & 10 & 11 & 12 & 13 & 14 & 15 & 16 \\
\hline \multirow[t]{2}{*}{$+/ \mathrm{T}$} & 1.5 & 1.7 & 1.6 & 2.0 & 2.3 & 2.8 & 3.2 & 4.0 & 5.1 & 6.1 & 6.1 & 6.8 & 7.5 & 7.5 & 7.9 & 8.2 \\
\hline & 1.9 & 2.0 & 2.4 & 2.8 & 3.1 & 3.9 & 4.8 & 5.7 & 6.7 & 7.6 & 8.5 & 9.4 & 10.2 & 11.3 & 12.4 & 12.5 \\
\hline $\mathrm{T} / \mathrm{T}-1$ & 1.7 & $1.7 \dagger$ & & & & & & & & & & & & & & \\
\hline $\mathrm{T} / \mathrm{T}-2$ & 1.4 & $1.3 \dagger$ & & & & & & & & & & & & & & \\
\hline $\mathrm{T} / \mathrm{T}-3$ & 1.6 & 1.6 & $1.4 \dagger$ & & & & & & & & & & & & & \\
\hline $\mathrm{T} / \mathrm{T}-4$ & 1.7 & 1.9 & 2.0 & 1.9 & $1.7 \dagger$ & & & & & & & & & & & \\
\hline $\mathrm{T} / \mathrm{T}-5$ & 1.8 & 1.6 & 1.6 & 1.6 & $1.6 \dagger$ & & & & & & & & & & & \\
\hline $\mathrm{T} / \mathrm{T}-6$ & 1.5 & 1.5 & 1.5 & 1.7 & 1.9 & 2.0 & $2.2 \dagger$ & & & & & & & & & \\
\hline $\mathrm{T} / \mathrm{T}-7$ & 1.8 & 1.6 & 1.6 & 1.8 & 2.0 & 2.0 & $2.3 \dagger$ & & & & & & & & & \\
\hline $\mathrm{T} / \mathrm{T}-8$ & 1.6 & 1.7 & 1.7 & 1.8 & 2.3 & 2.8 & 3.3 & 3.7 & $4.2 \dagger$ & & & & & & & \\
\hline T/T-9 & 1.9 & 2.0 & 2.1 & 2.4 & 2.8 & 3.4 & 4.0 & 5.1 & 5.5 & 6.3 & 7.1 & 7.9 & 8.7 & 8.9 & $9.0 \dagger$ & \\
\hline $\mathrm{T} / \mathrm{T}-10$ & 1.6 & 1.7 & 1.9 & 2.4 & 2.5 & 2.5 & 2.6 & 2.8 & 3.0 & 3.6 & 3.8 & 4.2 & 4.6 & 5.3 & n.d. & $5.6^{*}$ \\
\hline $\mathrm{T} / \mathrm{T}-11$ & 1.8 & 2.0 & 2.2 & 2.4 & 2.3 & 2.5 & 2.8 & 3.2 & 3.8 & 4.2 & 4.5 & 5.0 & 5.6 & 6.5 & n.d. & $6.7 *$ \\
\hline $\mathrm{T} / \mathrm{T}-12$ & 1.7 & 1.7 & 1.8 & 2.3 & 3.2 & 3.3 & 3.9 & 4.6 & 5.5 & 6.3 & 7.3 & 7.9 & 8.4 & 8.9 & 10.0 & $11.3^{*}$ \\
\hline
\end{tabular}

Presented are the weights (in grams) compared to a control sample of nine $+/ \mathrm{T}$ sibs (minimum and maximum weight only). T/T animals that reached adulthood are marked by an asterisk (*). nd $=$ not determined

\section{Discussion}

Caspr5-2 appears to be essential for viability

Homozygous carriers of a reciprocal translocation usually have a balanced karyotype and, thus, are phenotypically inconspicuous. In this work we identified a reciprocal translocation leading to the perinatal death of homozygous translocation carriers. Cytogenetic and subsequent molecular mapping of the breakpoints disclosed a simple breakage and fusion event in derivative $\operatorname{chr} 1^{8}$ but a more complex chromosomal rearrangement in chr $8^{1}$ : the transposition of an $\sim 2.5-\mathrm{Mb}$ fragment within the distal, translocated part of chr 1. Complex rearrangements associated with apparently balanced reciprocal translocations have recently been reported to be common phenomena in patients with abnormal phenotypes (Ciccone et al. 2005; Gribble et al. 2005). Such rearrangements could be identified only by molecular rather than routine cytogenetic mapping, emphasizing the importance of molecular analyses in cases of phenotypic abnormalities associated with apparently simple chromosomal rearrangments.

In the rearrangement presented here, only very few nucleotides had been lost during the four breakage and fusion events. Thus, loss of a complete gene can be excluded. However, translocation and transposition could have led to gene disruption at any of the four breakpoints, three in chr 1 and one in chr 8 . Screening of public databases for potentially disrupted genes revealed that only a single gene, Caspr5-2 (accession No. BN000866), an ortholog of human CASPR5 (Traut et al. 2006) and located in one of the breakpoint regions of chr 1, was disrupted. This was then confirmed experimentally by RT-PCR analysis and by in situ hybridizations to transcripts in translocation homozygotes.

Caspr5-2 consists of 24 exons and is predicted to encode a protein of 1292 amino acids. It extends over a genomic region of more than $700 \mathrm{~kb}$ and, thus, represents a large target for gene disruption. As predicted by the program SignalP v3.0 (http://www.cbs.dtu.dk) (Bendtsen et al. 2004), the first 24 amino acids of mouse Caspr5-2 define a signal peptide encoded by exon 1 . In the present study, Caspr5-2 is disrupted in intron 1; this disruption leads to the separation of the $5^{\prime}$ regulatory region, including exon 1 , from the rest of the gene. With the $5^{\prime}$ region removed, it is unlikely that the translocated remainder of Caspr5-2 would be correctly transcribed in time and tissue. In fact, our in situ hybridization experiments with Caspr5-2 antisense oligonucleotides, located in exons 6, 9, and 14-15 and 739, 1406 , and $2168 \mathrm{bp}$, respectively, downstream of the translational start site in the mRNA, demonstrated that Caspr5-2 transcription downstream of exon 1 is abrogated in translocation homozygotes. On the other hand, the creation of a chimeric gene with exon 1 of Caspr5-2 is unlikely because no genes were found in the close vicinity downstream of the chr 8 breakpoint. Hence, the most likely explanation for the lethal phenotype of T/T homozygotes is the loss of a functional Caspr5-2 protein due to the disruption of the Caspr5-2 gene between exons 1 and 2 .

In rare instances of chromosome breakage and fusion events, far-ranging position effects such as the silencing or activation of distant genes due to the separation from or 
juxtaposition with an enhancer element, respectively, had been described (Kleinjan and van Heyningen 1998). For lack of a suitable test system, we have no hint of such a mechanism in T/T mice, but we also cannot completely exclude the existence of such effects on genes located in close proximity to the breakpoints.

Caspr5-2 may play an essential role in cell recognition and adhesion in the central nervous system

A single Caspr5 gene has been identified in human and many other vertebrates, the only exception being the rodent lineage with up to four homologs, which probably arose by gene duplications (Traut et al. 2006). Besides Caspr5-2, the mouse has two more paralogs, Caspr5-1 and Caspr5-3. All three paralogs are similar in their exceptionally large size and neuronal expression, from early developmental stages to adulthood. Caspr5-2 shows the most widespread and highest expression among the three paralogs. Moreover, only Caspr $5-2$ is highly expressed in the embryonic forebrain and in the adult brain's granule cell layer of the olfactory bulb, the cortical layers $2 / 3$, the dentate gyrus of the hippocampus, and the Purkinje cell layer of the cerebellum.

Mouse Caspr5 proteins have more than a 95\% similarity among each other and show a high degree of sequence and domain conservation with Caspr1 to Caspr4, which are mainly, yet not exclusively, synthesized in neurons. The spatial expression patterns of the Caspr 5 genes largely overlap with that of the other Caspr genes, except for the white matter expression of Caspr2, Caspr3, and Caspr4 (Peles et al. 1997; Poliak et al. 1999; Spiegel et al. 2002; Traut et al. 2006). Caspr1 and Caspr2 are multidomain transmembrane proteins and located in different specific substructures of the node of Ranvier which is essential for the saltatory signal conduction in myelinated axons. Disturbance of axon myelination causes heritable neurologic disorders and myelinopathies of the peripheral and central nervous system such as Charcot-Marie-Tooth disease or multiple sclerosis (Zhou and Griffin 2003). Just recently, CASPR2 (CNTNAP2) has been identified as a susceptibility gene in autism spectrum disorders (Alarcon et al. 2008; Arking et al. 2008; Bakkaloglu et al. 2008). In an animal model, Caspr1-deficient mice exhibited cytoskeletal disorganization and degeneration of axons from Purkinje cells due to the disruption of axoglial junctions (Garcia-Fresco et al. 2006). The Casprl null mice were viable, yet displayed severe motor defects. Caspr 2 null mice were also viable and, in contrast to Casprl null animals, showed no obvious signs of behavioral abnormalities but rather the redistribution of Shaker-like potassium channels at the cellular level (Poliak et al. 2003). The less well-examined Caspr3 and Caspr4 proteins were found in different regions of the central and peripheral nervous system and were proposed to play a role in cell recognition (Spiegel et al. 2002).

From its expression pattern and structural similarity with Caspr1 to Caspr4, it is likely that the Caspr5-2 protein has similar properties, i.e., it may be involved in proper cell recognition and interaction presumably between axons and glia cells in different regions of the central nervous system. In contrast to Caspr1 and Caspr2, however, Caspr 5-2 appears to be essential for survival.

In summary, we have identified a Caspr5-2 null mutation as the most probable cause of perinatal lethality of homozygous mutation carriers. Rare homozygous survivors may be rescued by one of the two other Caspr 5 paralogs, depending on still unknown mechanisms during embryonic development.

Acknowledgments The excellent technical assistance of Ulrike Eickhoff, Constanze Reuter, and Elzbieta Manthey is gratefully acknowledged.

Open Access This article is distributed under the terms of the Creative Commons Attribution Noncommercial License which permits any noncommercial use, distribution, and reproduction in any medium, provided the original author(s) and source are credited.

\section{References}

Alarcon M, Abrahams BS, Stone JL, Duvall JA, Perederiy JV et al (2008) Linkage, association, and gene-expression analyses identify CNTNAP2 as an autism-susceptibility gene. Am J Hum Genet 82:150-159

Arking DE, Cutler DJ, Brune CW, Teslovich TM, West K et al (2008) A common genetic variant in the neurexin superfamily member CNTNAP2 increases familial risk of autism. Am J Hum Genet 82:160-164

Bakkaloglu B, O'Roak BJ, Louvi A, Gupta AR, Abelson JF et al (2008) Molecular cytogenetic analysis and resequencing of contactin associated protein-like 2 in autism spectrum disorders. Am J Hum Genet 82:165-173

Beechey CV, Cattanach BM, Blake A, Peters J (2004) Mouse imprinting map. MRC Mammalian Genetics Unit, Oxfordshire, UK

Bendtsen JD, Nielsen H, von Heijne G, Brunak S (2004) Improved prediction of signal peptides: SignalP 3.0. J Mol Biol 340:783795

Birnboim HC, Doly J (1979) A rapid alkaline extraction procedure for screening recombinant plasmid DNA. Nucleic Acids Res 7:1513-1523

Ciccone R, Giorda R, Gregato G, Guerrini R, Giglio S et al (2005) Reciprocal translocations: a trap for cytogenetists? Hum Genet 117:571-582

Coman I, Aigrot MS, Seilhean D, Reynolds R, Girault JA et al (2006) Nodal, paranodal and juxtaparanodal axonal proteins during demyelination and remyelination in multiple sclerosis. Brain 9:9

Garcia-Fresco GP, Sousa AD, Pillai AM, Moy SS, Crawley JN et al (2006) Disruption of axo-glial junctions causes cytoskeletal disorganization and degeneration of Purkinje neuron axons. Proc Natl Acad Sci USA 103:5137-5142 
Gribble SM, Prigmore E, Burford DC, Porter KM, Ng BL et al (2005) The complex nature of constitutional de novo apparently balanced translocations in patients presenting with abnormal phenotypes. J Med Genet 42:8-16

Kleinjan DJ, van Heyningen V (1998) Position effect in human genetic disease. Hum Mol Genet 7:1611-1618

Ochman H, Medhora MM, Garza D, Hartl DL (1990) Amplification of flanking sequences by inverse PCR. In: PCR protocols: a guide to methods and applications. Academic Press, New York, pp 219-227

Osoegawa K, Tateno M, Woon PY, Frengen E, Mammoser AG et al (2000) Bacterial artificial chromosome libraries for mouse sequencing and functional analysis. Genome Res 10:116-128

Peles E, Nativ M, Lustig M, Grumet M, Schilling J et al (1997) Identification of a novel contactin-associated transmembrane receptor with multiple domains implicated in protein-protein interactions. EMBO J 16:978-988

Poliak S, Peles E (2003) The local differentiation of myelinated axons at nodes of Ranvier. Nat Rev Neurosci 4:968-980

Poliak S, Gollan L, Martinez R, Custer A, Einheber S et al (1999) Caspr2, a new member of the neurexin superfamily, is localized at the juxtaparanodes of myelinated axons and associates with K+ channels. Neuron 24:1037-1047

Poliak S, Salomon D, Elhanany H, Sabanay H, Kiernan B et al (2003) Juxtaparanodal clustering of Shaker-like $\mathrm{K}+$ channels in myelinated axons depends on Caspr2 and TAG-1. J Cell Biol 162:1149-1160

Sambrook J, Russell D (2001) Molecular cloning: a laboratory manual, 3rd edn. Cold Spring Harbor Laboratory Press, Cold Spring Harbor, NY

Seabright M (1971) A rapid banding technique for human chromosomes. Lancet 2:971-972

Spiegel I, Salomon D, Erne B, Schaeren-Wiemers N, Peles E (2002) Caspr3 and caspr4, two novel members of the caspr family are expressed in the nervous system and interact with PDZ domains. Mol Cell Neurosci 20:283-297

Traut W, Weichenhan D, Himmelbauer H, Winking H (2006) New members of the neurexin superfamily: multiple rodent homologues of the human CASPR5 gene. Mamm Genome 17:723731

Wisden W, Morris BJ (1994) In situ hybridization with synthetic oligonucleotide probes. In: Wisden W, Morris BJ (eds) In situ hybridization protocols for the brain. Academic Press, London, UK, pp 9-34

Wolswijk G, Balesar R (2003) Changes in the expression and localization of the paranodal protein Caspr on axons in chronic multiple sclerosis. Brain 126:1638-1649

Zhou L, Griffin JW (2003) Demyelinating neuropathies. Curr Opin Neurol 16:307-313 